\title{
COMMERCIAL ALTERNATIVES FOR THE LOW PRICE JOINTS OF CULLING COWS: HAMBURGERS REDUCED IN SALT AND FAT
}

\author{
B. Panea*, G. Ripoll \\ Centro de Investigación y Tecnología Agroalimentaria de Aragón (CITA). Instituto Agroalimentario de Aragón \\ - IA2 (CITA-Universidad de Zaragoza). Avda. Montañana 930, 50059 Zaragoza, Spain \\ * Correspondence: bpanea@aragon.es; Tel.: +34-976-716443
}

\begin{abstract}
The consumer's acceptability of hamburgers elaborated with the flank of culling cows in which the content of salt or fat had been partially replaced was studied. A mixture of potassium chloride, potassium ferrocyanide and sodium ferrocyanide was used as substitutes for the salt. Oat flakes or a mixture of chia and flax seeds were used as substitutes for the fat. The hamburgers were tasted by 34 consumers. Consumers did not detect significant differences between the control and the rest of the formulations. Neither the gender nor the age of the consumers influenced the sensory appraisal. However, many comments regarding texture failures were recorded. Therefore, the substitution of salt and / or fat in the composition of hamburgers made with the flank of cows is a viable alternative for the commercialization of these pieces of low commercial value as long as the texture of the same is adjusted to resemble it to the control.
\end{abstract}

Keywords: low fat; salt reduction; meat product; sensory; beef

\section{Introduction}

Meat of culling cows have little commercial value, since the consumer perceives that it is hard and has an intense flavor. However, in Spain there are approximately 2,800,000 cows, which represent $44 \%$ of the national cattle census (INE, 2017). In Aragon, the bovine census is around over 111,000 heads, which produce $32,000 \mathrm{Tm}$ of meat. The $8 \%$ of that meat comes from culling cows (INE, 2016). Therefore, it is important to look for strategies that increase the value of this meat. One of the most commonly applied strategies and that has known an important development in recent years, is the dry ageing. The dry ageing allows to increase the tenderness of the meat by exposing it to very long ageing times (typically over a month) and is a product well accepted by consumers because it has a characteristic flavor and is perceived as a high quality product [1,2]. However, this technique can only be applied to the prime joints as loin (M. Longissimus thoracis et lumborum) because the prolonged storage increases the final price of the product and because had enough cover fat to protect the muscle from cold shortening and spoilage during the storage period. The flank represents $5.4 \%$ of the marketable proportion of the carcass, it is easy to extract and its meat has good technological aptitudes [3]. A good way to take advantage of the flank is elaborating minced products such as meatballs or hamburgers. Hamburgers are a product of great acceptance by consumers and their consumption is well installed and widely distributed [4]. However, it is a product perceived by a sector of consumers as unhealthy, since in its preparation is usually added lard, salt and other 
39 additives and numerous studies indicate that the consumption of beef is increasingly influenced by 40 nutritional and health considerations $[5,6]$.

41 One way to increase the consumption of hamburgers could be to meet the expectations of the consumers who look for healthier products with similar taste. Reducing the amount of salt or fat can cause technological problems [7] and can affect the sensory quality of the product [8]. However, replacing some ingredients with others beneficial to health we could get a new product with functional properties increasing its value. Consequently, when changing the composition of a product it is necessary to study its acceptability by the consumer. Therefore, the general objective of this work was to value the cow' carcass joint of lower price through the improvement of the nutritional profile of the hamburgers made with this meat. The specific objective was to study the acceptability of these hamburgers by consumers.

\section{Materials and Methods}

Hamburgers were prepared using the flank of 6 culling cows of Parda de Montaña slaughtered between 6.5 and 14.5 years of age, in an authorized abattoir by the EU (ES 10.01400 / LU CE). The live weight at slaughter ranged between $660 \mathrm{Kg}$ and $880 \mathrm{Kg}$. The carcasses were kept at $4{ }^{\circ} \mathrm{C}$ for 24 hour and then carcasses were cut longitudinally. The flanks were extracted and transported to laboratory vacuum packed. The meat was extracted from the bags, the fasciae, the cover fat and the coarse parts of connective tissue were removed and all the meat was cut and chopped as a single batch, using an Elma chopper (UDOM SL, Álava, Spain). The meat was minced twice, first with an $8 \mathrm{~mm}$ grater and then with a $5 \mathrm{~mm}$ grater. Once the meat was minced, were obtained 1 control batch and 4 experimental batches (Table 1):

- CONTROL BATCH. Beef, beef fat, water and common salt

62 - SEEDS BATCH. Beef, water and common salt. Substitute for fat: Natur Green Seeds Mixture super Omega (Laboratorios Almond S.L., Librillos, Spain). Composition: Chia seeds * (25\%), hemp * $(20 \%)$, golden flax * $(20 \%)$, brown milled flax $(20 \%)$ and brown flax $(15 \%) \bullet$ FLAKES BATCH. Beef, water and common salt. Substitute for fat: Integral Oat Flakes Bio, ECO CESTA (Biogran, S.L.,

66 Paracuellos de Jarama, Spain). SALT BATCH. Beef, beef fat and water. Substitute for salt: Salt for hypertensive patients. Composition: Potassium chloride, potassium ferrocyanide and sodium ferrocyanide (Selfoods SAU, Subirats, Barcelona). MIXED BATCH. Beef and water. Substitute for 
74 Table 1. Ingredients of the different batches of hamburgers and sought effect in each preparation.

\begin{tabular}{|c|c|c|c|c|c|c|c|}
\hline Formulation & Sought effect & $\begin{array}{c}\text { Lean } \\
\text { meat } \\
(\mathrm{g})\end{array}$ & $\begin{array}{l}\text { Water } \\
(\mathrm{g})\end{array}$ & $\begin{array}{c}\mathrm{NaCl} \\
(\mathrm{g})\end{array}$ & Others (g) & $\begin{array}{c}\text { Animal } \\
\text { fat added } \\
(\%)\end{array}$ & $\begin{array}{c}\mathrm{NaCl} \\
\text { added } \\
(\%)\end{array}$ \\
\hline Control & - & 1000 & 500 & 23 & Fat beef: $150 \mathrm{~g}$ & 9.0 & 1.4 \\
\hline Flakes & Fat reduction & 1000 & 500 & 23 & Oats flakes: $200 \mathrm{~g}$ & 0.0 & 1.3 \\
\hline Seeds & Fat reduction & 1000 & 500 & 23 & $\begin{array}{l}\text { Fat beef: } 30 \mathrm{~g} \\
\text { Seeds: } 120 \mathrm{~g}\end{array}$ & 1.8 & 1.4 \\
\hline Salt & Salt reduction & 1000 & 500 & 0 & $\begin{array}{c}\text { Fat beef: } 150 \mathrm{~g} \\
\text { Salt substitute: } 23 \mathrm{~g}\end{array}$ & 9.0 & 0.0 \\
\hline Mixed & $\begin{array}{l}\text { Salt reduction } \\
\text { Fat reduction }\end{array}$ & 840 & 500 & 0 & $\begin{array}{c}\text { Salt substitute: } 23 \mathrm{~g} \\
\text { Seeds: } 105 \mathrm{~g} \\
\text { Oats flakes: } 60 \mathrm{~g}\end{array}$ & 0.0 & 0.0 \\
\hline
\end{tabular}

Fat added was always and lonely cows' flanks fat.

The five mixtures were kept for 24 hours at $4{ }^{\circ} \mathrm{C}$. Then, 40 hamburgers were formed per batch, with an approximate weight of $40 \mathrm{~g} /$ hamburger. Each hamburger was individually packaged in a polypropylene container ( $0.95 \mathrm{~g} / \mathrm{cm}^{2}$, Linpac Packaging, LINPAC Senior Holdings Limited, Featherstone) identified with a number from 1 to 5 . Nutritional composition was estimated from the database published by Moreiras et al. (2007), (Table 2).

Table 2. Estimation of the nutritional composition of the hamburgers ( $\mathrm{g} / 100 \mathrm{~g}$ )

\begin{tabular}{lccccccc}
\hline & Protein & Fat & Carbohydrates & Moisture & NaCl & Fiber & Salt Substitute \\
\hline Control & 10.9 & 11.1 & 0.0 & 76.7 & 1.4 & 0.0 & 0.0 \\
Flakes & 12.2 & 2.9 & 6.5 & 74.5 & 1.3 & 1.2 & 0.0 \\
Seeds & 12.6 & 2.5 & 0.3 & 76.7 & 1.4 & 2.1 & 0.0 \\
Salt & 10.9 & 11.1 & 0.0 & 76.7 & 0.0 & 0.0 & 1.4 \\
Mixed & 18.2 & 6.8 & 3.8 & 64.4 & 0.0 & 3.6 & 1.6 \\
\hline
\end{tabular}

Estimated from nutritional labels of ingredients.

For the test, 40 consumers were recruited and 34 valid surveys were collected. The participation of consumers was voluntary and anonymous. No personal data was asked apart from age and gender and consumers were not economically compensated. Participants were informed about the purpose of the study and their implicit consent for the use of the information provided, in accordance with European regulations (U.E., 2010). The test was carried out using the home-test technique. The hometest is useful to collect information about the product in a realistic situation and is recommended when the number of samples to be tested is low [9].Each consumer was given three hamburgers with a template and instructions to perform the test. The distribution was made following a design balanced by blocks to obtain the same number of judgments for all the batches. Consumers were asked to assess for each sample the quality of the flavor, the juiciness and the quality of the texture, using for this an unstructured scale of 1 (very bad, very little juicy, very bad texture) to 10 (very good, very juicy, very good texture). In addition, they were given the option to express additional adjectives by asking them if they had found any unexpected flavor or texture and if so, if they had liked it. 


\section{3. Results and discussion}

112 Table 2 shows that all the hamburgers had a similar amount of protein (around 11\%), except the 113 MIXED BATCH, which had about $18 \%$ protein. The reduction of fat was $74 \%$ in the FLAKES BATCH, $11477 \%$ in the SEEDS BATCH and 39\% in the MIXED BATCH. In the FLAKES BATCH the fat reduction

\section{Statistical analysis}

The XLSTAT program v.3.05 (Addinsoft, USA) was used. The three notes of each consumer were standardized with respect to their own mean to eliminate the error due to the different use of the scale by different consumers. So, the note of each consumer has been expressed as the deviation of its own media. The variables thus transformed are continuous and therefore can be treated with an analysis of variance. Therefore, a GLM was made with the composition of the hamburgers and the gender and age of the consumers as fixed effects. The additional adjectives were grouped by semantic similarity, assigning a code to each group. The effect of the hamburger composition and the gender and age of the consumers on the frequency of appearance of the additional adjectives was used a Chisquare test. implied an increase of $6.5 \%$ of the carbohydrate content, while in the SEEDS BATCH this content only increased by $0.3 \%$ and in the MIXED BATCH it was a 3.8\% Therefore, it is expected that the energy content of the SEEDS BATCH will be lower than the rest. The salt was reduced by $1.4 \%$ both in the SAL BATCH and in the MIXED BATCH.

The consumers sample was balanced by gender and age (Table 3). Table 4 shows the significance of the effects studied (value of $\mathrm{p}$ ) on the notes of flavor, juiciness and texture. No differences were found between batches for any of the variables studied. No differences due to gender or age of consumers were found. Table 5 shows the frequency of occurrence of each additional adjective by batch. Only negative adjectives are shown, since they are the ones that provide more information about the viability of the proposed composition. It can be seen that the two most frequent adjectives were "Texture failures" (29\% of cases) and "Strange" (21\%). In addition, the SALT and FLAKES batches collected more comments than the rest (27\% each). There was found an effect of the batch on the frequency of appearance of the different adjectives $(p=0.004)$. Interestingly, the adjective "salty" appears more often in the CONTROL and SALT batches than in the rest, maybe because the addition of seeds and / or flakes masked the taste of the salt, especially in the FLAKES batch, in which the frequency of appearance for "salty" was less than expected.

The batches FLAKES and SEEDS presented greater frequency of "faults of texture", which would to imply that either the ingredients used or the proportions in which they were used are not adequate. Regarding the additional adjectives, women tended to describe samples as "salty" more frequently ( $p$ $=0.095)$, and the adjective "strange" less often $(p=0.076)$ than men. No gender effect was found on the frequency of appearance of adjectives $(p=0.266)$.

Table 3. Frequencies for consumers' age and gender (percentages over valid cases)

\begin{tabular}{crc}
\hline & Men & Women \\
\hline$\leq 40$ years & 55 & 45 \\
$>40$ years & 45 & 55 \\
\hline
\end{tabular}


137 Table 4. $p$ value of GLM with batch, and consumers' gender and age as fix effects.

\begin{tabular}{lccc}
\hline & Batch & Gender & Age \\
\hline Taste & 0.069 & 0.717 & 0.274 \\
Juiciness & 0.164 & 0.717 & 0.313 \\
Texture & 0.505 & 0.880 & 0.750 \\
\hline
\end{tabular}

138

139 Table 5. Number of cases for additional adjectives in each experimental batch

\begin{tabular}{|c|c|c|c|c|c|c|}
\hline & Control & Flakes & Seeds & Salt & Mixed & TOTAL \\
\hline Sour & & 1 & & & & 1 \\
\hline Bitter & & & & 3 & 2 & 5 \\
\hline Raw & & 1 & & 1 & & 2 \\
\hline Tasteless & & 2 & & 1 & 2 & 5 \\
\hline Texture failure & & 9 & 5 & 1 & 3 & 18 \\
\hline Strange & & 4 & 4 & 2 & 3 & 13 \\
\hline Salty & 5 & & & 4 & & 9 \\
\hline Sexual & & & & 1 & & 1 \\
\hline Old & 1 & & 1 & 4 & 2 & 8 \\
\hline TOTAL & 6 & 17 & 10 & 17 & 12 & 62 \\
\hline
\end{tabular}

\section{Discussion}

142 The lack of effect of sociodemographic variables would be in agreement with other studies [10-12].

143 Most of the articles that study the effect of the hamburger composition focused on microbiological

144 risks [13], on changes in chemical composition [14] or in the useful life of the product [15], but very

145 few contemplate the consumers perception.

146 The reduction of salt in meat products implies a decrease in the solubilisation of miofibrilar proteins,

147 which causes an increase in tenderness [16]. Accordingly, Tobin, O'Sullivan, Hamill and Kerry [6],

148 studying the effect of reducing salt and/or fat in different combinations, concluded that the reduction

149 of salt produced hamburgers more tender and that the higher the fat content the higher the frequency

150 of off-flavors occurrence. However, some authors [17], working with hamburgers in which the salt

151 was partially replaced by potassium lactate or sodium metasilicate, point out that the trained panel

152 was not able to detect differences between treatments for the flavor of the hamburgers and Mora-

153 Gallego, Guardia, Serra, Gou and Arnau [11] reported that the addition of $0.64 \% \mathrm{KCl}$ in dry fermented

154 sausages did not modify sensory perception. Similarly, other authors [18] found no effect of the

155 addition of $3 \%$ potassium lactate on the sensory quality of Frankfurt-type sausages.

156 The effect of fat substitution is not conclusive in the literature and the effect depends on the meat 157 product considered, on the substitutes used and on the proportion in which they are used. The most 158 commonly used substitutes are vegetable oils, carbohydrates and fiber-rich foods.

159 In our experiment, consumers did not detect the replacement of fat. An study in which was

160 elaborated hamburgers with different pieces of beef with different composition in fatty acids and 
161 aromatic compounds [19] showed that these differences do not affect the sensory quality of the 162 hamburgers because phospholipid are the responsible of the flavor and aromatic compounds but not 163 to the triglycerides. Other studies [5] reported that hamburgers with $10 \%$ of fat were slightly less juicy 164 than those with $20 \%$ fat, without differences in any of the other sensory attributes studied and some 165 authors [6] found that that hamburgers with higher fat content were also valued as more salty.

166 However, there is considerable consensus in the literature indicating that the type of compound that 167 replaces fat influences sensory perception. The flavor to meat has been negatively correlated with the 168 amount of fat and the off-flavors increased as the fat content did [6]. Thus, [20] found that the 169 addition of oils with a high PUFA n 3 content affected negatively the sensory quality of the sausages. 170 In the same way, [21], point out that the increase of long chain fatty acids (EPA and DHA) affected 171 negatively flavor and increased the amount of off-flavors in hamburgers. Similarly, [22], reported 172 that the incorporation of olive cake to hamburgers did not affect their sensory perception in 173 concentrations of $4 \%$ but there was a detriment when the substitution reached $6 \%$. This same negative 174 effect of an excess of fat has also been found in other meat products such as, for example, sunflower 175 oil in sausage [11]. In a performed test [4] on beef hamburgers in which the fat had been partially 176 replaced by chia and flax microparticles authors found that the substitution reduced the sensory 177 quality of the hamburgers. The panellists rated the hamburgers with chia as bitter, dry, with a fatty 178 aroma, difficult to chew, rancid, acidic and strange in appearance. Flax oil provided positive 179 attributes (mild and pleasant taste) but was described as oily in appearance. In the present 180 experiment, the hamburgers with a different fat were those from the SEEDS batch, but there was no 181 an increase in off-flavors comments frequency and the comments about the texture were probably 182 due more to the crunchy effect of the seeds than to the properties of flax oil.

183 In an study [23] with manufactured 8 batches of hamburgers, all with the same content in fat (13\%) 184 and salt $(0.6 \%)$ but with different combinations of maltodextrin, collagen and textured soy, the 185 authors found that maltrodextrin provided more moisture to hamburgers, while collagen caused an 186 increase in hardness. Piñero, et al. [24] used oatmeal as a source of beta-glucan to reduce the fat 187 content of the hamburgers improving the water retention and juiciness, but make taste worst. Other 188 works also indicate that the addition of oats helps to retain water and increases the juiciness of 189 hamburgers [25] In our work, we did not find significant differences between batches for juiciness, 190 but contrary to expected the FLAKES batch showed the lowest notes in juiciness. In addition, the 191 FLAKES and the SEEDS batches modified the visual appearance and texture in the mouth and they 192 were often described as strange. This result agreed with other authors [26] which in a work with 193 hamburgers elaborated with minced meat concluded that the degree of ground influenced the 194 consumers' acceptability.

\section{Conclusions}

In the conditions of the present work it can be concluded that there were no differences between influenced the sensory appreciation. However. meither the gender nor the age of the consumers recorded. Therefore, the substitution of salt and / or fat in the composition of hamburgers made with the culling cow flanks meat would be a viable alternative for the commercialization of these joint as 
203 Author Contributions: Conceptualization, BEGOÑA PANEA; Data curation, BEGOÑA PANEA; Formal 204 analysis, BEGOÑA PANEA and Guillermo Ripoll; Funding acquisition, BEGOÑA PANEA; Investigation, BEGOÑA PANEA; Methodology, BEGOÑA PANEA; Project administration, BEGOÑA PANEA; Resources, BEGOÑA PANEA; Supervision, BEGOÑA PANEA; Validation, BEGOÑA PANEA and Guillermo Ripoll; Visualization, BEGOÑA PANEA and Guillermo Ripoll; Writing - original draft, BEGOÑA PANEA and Guillermo Ripoll; Writing - review \& editing, BEGOÑA PANEA and Guillermo Ripoll.

210 Acknowledgments: To Isabel Casasús and ARAPARDA, for the technical support and the animal 211 material used. The authors are members of the MARCARNE Network (CYTED PR115RT0034).

212 Conflicts of Interest: The authors declare no conflict of interest. The founding sponsors had no role in the design of the study; in the collection, analyses, or interpretation of data; in the writing of the manuscript, and in the 214 decision to publish the results. 


\section{References}

$217 \quad$ 1. Li, X.; Babol, J.; Bredie, W.L.; Nielsen, B.; Tomankova, J.; Lundstrom, K. A comparative study of

218 beef quality after ageing longissimus muscle using a dry ageing bag, traditional dry ageing or vacuum package ageing. Meat Sci, 2014, 97(4), 433-442. .

2. $\quad$ Prieto, N.; Singh, R.; Schmidt, B.; Thacker, R.; Larsen, I.L.; Juárez, M.; Aalhus, J.L. In-the-bag dry ageing as a strategy to produce value-added beef with enhanced flavour profiles. Meat Science 2018, 137, 282.

Albertí, P.; Lahoz, F.; Tena, R.; Jaime, S.; Sañudo, C.; Olleta, J.; Campo, M.; Panea, B.; Pardos, J.

5. Selani, M.M.; Shirado, G.A.; Margiotta, G.B.; Saldana, E.; Spada, F.P.; Piedade, S.M.; ContrerasProducción y rendimiento carnicero de siete razas bovinas españolas faenadas a distintos pesos. Informaciones Técnicas 2001, 101, 16.

Heck, R.T.; Vendruscolo, R.G.; de Araujo Etchepare, M.; Cichoski, A.J.; de Menezes, C.R.; Barin, J.S.; Lorenzo, J.M.; Wagner, R.; Campagnol, P.C.B. Is it possible to produce a low-fat burger with a healthy n-6/n-3 pufa ratio without affecting the technological and sensory properties? Meat Sci 2017, 130, 16-25. Castillo, C.J.; Canniatti-Brazaca, S.G. Effects of pineapple byproduct and canola oil as fat replacers on physicochemical and sensory qualities of low-fat beef burger. Meat Sci 2016, 112, 69-76.

6. Tobin, B.D.; O'Sullivan, M.G.; Hamill, R.M.; Kerry, J.P. Effect of varying salt and fat levels on the sensory quality of beef patties. Meat Science 2012, 91, 460-465.

7. Hughes, E.; Cofrades, S.; Troy, D. Effects of fat level, oat fibre and carrageenan on frankfurters formulated with 5, 12 and 30\% fat. Meat science 1997, 45, 273-281. Jiménez-Colmenero, F.; Triki, M.; Herrero, A.M.; Rodríguez-Salas, L.; Ruiz-Capillas, C. Healthy oil combination stabilized in a konjac matrix as pork fat replacement in low-fat, pufa-enriched, dry fermented sausages. LWT - Food Science and Technology 2013, 51, 158-163.

12. Nordin, S.; Broman, D.A.; Garvill, J.; Nyroos, M. Gender differences in factors affecting rejection of

13. Juneja, V.K.; Cadavez, V.; Gonzales-Barron, U.; Mukhopadhyay, S. Modelling the effect of ph,

Santa Cruz, M.; Martínez, C.; Varela, P. Principios básicos del análisis sensorial. Estimación de la vida útil sensorial de los alimentos, 1 st edn. Martín Impresores SL, Madrid 2005, 24-26.

14. Barriuso, B.; Ansorena, D.; Calvo, M.I.; Cavero, R.Y.; Astiasarán, I. Role of melissa officinalis in cholesterol oxidation: Antioxidant effect in model systems and application in beef patties. Food Research International 2015, 69, 133-140. attitudes towards quality attributes of lamb meat. Food Qual Prefer 2012, 26, 211-220. acceptability of potassium chloride and sunflower oil addition in small-caliber non-acid fermented sausages with a reduced content of sodium chloride and fat. Meat Sci 2016, 112, 9-15. food in healthy young swedish adults. Appetite 2004, 43, 295-301. sodium chloride and sodium pyrophosphate on the thermal resistance of escherichia coli o157:H7 in ground beef. Food Research International 2015, 69, 289-304.

Hayes, J.; Stepanyan, V.; Allen, P.; O'grady, M.; Kerry, J. Effect of lutein, sesamol, ellagic acid and olive leaf extract on the quality and shelf-life stability of packaged raw minced beef patties. Meat science 2010, 84, 613-620. 
258 16. Schwartz, W.; Mandigo, R. Effect of salt, sodium tripolyphosphate and storage on restructured pork. 259 Journal of Food Science 1976, 41, 1266-1269.

$260 \quad$ 17. Quilo, S.; Pohlman, F.; Brown, A.; Crandall, P.; Dias-Morse, P.; Baublits, R.; Aparicio, J. Effects of potassium lactate, sodium metasilicate, peroxyacetic acid, and acidified sodium chlorite on physical, chemical, and sensory properties of ground beef patties. Meat science 2009, 82, 44-52.

18. Nunez de Gonzalez, M.T.; Keeton, J.T.; Acuff, G.R.; Ringer, L.J.; Lucia, L.M. Effectiveness of acidic

19. Kerth, C.R.; Harbison, A.L.; Smith, S.B.; Miller, R.K. Consumer sensory evaluation, fatty acid

21. Jiang, T.; Busboom, J.R.; Nelson, M.L.; Mengarelli, R. Omega-3 fatty acids affected human perception

22. Hawashin, M.D.; Al-Juhaimi, F.; Ahmed, I.A.M.; Ghafoor, K.; Babiker, E.E. Physicochemical,

24. Piñero, M.P.; Parra, K.; Huerta-Leidenz, N.; Arenas de Moreno, L.; Ferrer, M.; Araujo, S.; Barboza,

25. Desmond, E.; Troy, D.; Buckley, D. Comparative studies of nonmeat adjuncts used in the manufacture beef. Oklahoma State University, 2016. 